\title{
MUSICOTERAPIA NA ESCOLA - ESTRATÉGIA DE ENFRENTAMENTO DO BULLYING: UMA REVISÃO INTEGRATIVA
}

\section{MUSICOTERAPY IN SCHOOL - BULLYING COUNSELING STRATEGY: INTEGRATIVE REVIEW}

\section{RESUMO}

Introdução: A música pode ser um meio de enfrentamento dos diversos problemas na juventude. Objetivo: Identificar estudos que utilizem a musicoterapia como forma de enfrentamento do Bullying nas escolas. Método: Revisão integrativa que utilizou o acrônimo PCC, sendo, População: adolescentes; Conceito: música e musicoterapia e; Contexto: Escola. Na base de dados PubMed e Revista Music Therapy Perspectives. Resultados: Foram identificados 73 artigos, sendo eliminados 59 por título e 57 por resumo. Um total de 2 estudos foram incluídos. Dentre os dados extraídos constam: idade da população, tipo de intervenção musical e resultados do uso da música. Conclusão: A musicoterapia em contexto escolar atua com foco em alunos com problemas comportamentais, incluindo perpetradores do Bullying, favorecendo a empatia, autoconhecimento, autoestima, auxiliando nas dificuldades de expressão de pensamentos e sentimentos, na autorregulação emocional, contribuindo com a redução da agressividade. Diversos recursos e técnicas musicais foram identificados nos estudos incluídos.

PALAVRAS-CHAVE: Adolescente. Musicoterapia. Música. Violência. Bullying. Escola

\section{ABSTRACT}

Introduction: Music as a mean of coping with several problems in youth. Objective: To identify studies that uses music therapy as a way of coping with Bullying in schools. Method: Integrative review using the acronym PCC, being, Population: adolescents; Concept: music and music therapy; Context: School in the PubMed database and Music Therapy Perspectives Journal. Results: A total of 73 articles were identified, 59 excluded by title and 57 excluded by abstract. A total of 2 studies are included. Conclusion: Music therapy in a school context focuses on children with behavioral problems, including perpetrators of Bullying, It favors empathy, self-knowledge, self-awareness, self-esteem, helping in the difficulties of expressing thoughts and feelings, in emotional self-regulation, thus helping to reduce aggression. Several resources and musical techniques were used in the included studies.

KEYWORDS: Adolescent. Music Therapy. Music. Violence. Bullying. School

1 Mestranda em Saúde Coletiva - UNIFESP/EPM. Especialização em Equipe Multiprofissional do Centro de Atenção e Apoio ao Adolescente, Departamento de Pediatria, Especialização em Educação com área de concentração em Filosofia e Ensino de Filosofia; Bacharelado em Musicoterapia (FPA)

2 Prof. Adjunto Dr e Chefe do Setor de Medicina do Adolescente UNIFESP/EPM; Professor Permanente do Programa de PósGraduação Educação e Saúde na Infância e Adolescência, UNIFESP/Departamento de Educação. Autora Correspondente: Endereço: Rua Botucatu, 715, Vila Clementino, CEP 04023-062, São Paulo, SP, Brasil. E-mail: sylviavitalle@gmail.com 


\section{Introdução}

Bullying é uma forma de violência que, geralmente ocorre entre jovens em idade escolar, nas escolas e lugares onde frequentam. Dentre as inúmeras formas de violência, comumente caracteriza-se por agressões físicas (tapas e chutes), verbais (apelidos maldosos e xingamentos), morais (intimidações e ameaças) e sexuais (assédio e abuso) (ALMEIDA, CAVALCANTE, SILVA, 2008). Em 2015 foi instituído em território nacional o Programa de Combate à Intimidação Sistemática, também conhecida como Bullying (IBGE, 2016).

A violência escolar e Bullying violam os direitos fundamentais das crianças e adolescentes. Segundo o Estatuto da Criança e do Adolescente (ECA, 1990), os artigos, 3, 4 e 5, por exemplo, abordam aspectos que vêem de encontro com a questão. Ser, portanto vítima de Bullying, está em desacordo com os itens do estatuto como 1) receber proteção da sociedade (família, comunidade, escola, professores); 2) não poder gozar em liberdade e dignidade das oportunidades de desenvolvimento físico, mental, social e espiritual 3) Não ser objeto de negligência, discriminação, exploração, violência, crueldade e opressão. (ECA, 1990).

No Brasil, assim como no mundo, a violência escolar e Bullying é uma preocupação que afeta não apenas o indivíduo, mas à qualidade da educação, e a saúde pública, tendo um impacto nas contas públicas, uma vez que o perpetrador do Bullying, além de geralmente desistir do aprendizado, poderá apresentar no futuro, comportamentos criminosos e antissociais, baixa qualificação, e menos aderência aos programas sociais de ajuda. Estima-se que no Brasil, o impacto econômico da violência contra crianças e adolescentes seja próximo a 19 bilhões de dólares por ano, sendo 943 milhões destes, relativos à violência nas escolas (UNESCO, 2017).

A prática de Bullying é predominante na população LGBT, correspondendo a 85 por cento do total de jovens vítimas (UNESCO, 2017). Na Pesquisa Nacional de Saúde do Escolar (IBGE, 2016), a temática começou a ser invetigada a partir de 2015 , onde $61,9 \%$ dos estudantes disseram que foram bem tratados pelos colegas nos últimos 30 dias. Em relação a sentir-se humilhado por colegas, $7,4 \%$ responderam que sofreram provocações na maior parte do tempo. Há maior incidência de Bullying no Estado de São Paulo.

Os principais motivos do Bullying, em dados mundiais, apontam relação com divergência de capacidade física (deficiência física ou cognitiva); gênero; pobreza e status social; divergência étnica, linguística ou cultural (estrangeiros); aparência física e; orientação sexual (identidade de gênero e expressão).

As consequências para a vítimas são de médio a longo prazo e, compreendem: distúrbios de ansiedade, depressão, transtorno alimentar, abuso de drogas, pensamentos suicidas, tentativa de suicidio, dificuldades interpessoais, isolamento e, baixa auto-estima. O Bullying também afeta o desempenho escolar por medo de ir à escola, dificuldade em manter-se atento e, desistência dos estudos (UNESCO, 2017) (IBGE, 2016).

Segundo Freire e Aires (2012), o fenômeno do Bullying difere-se a cada contexto, portanto, quando se fala de enfrentamento, não existe uma receita pronta, é necessário examinar a situação em cada local que acontece e traçar um plano para o contexto. Considera como teoria de apoio, que

"O individuo tem papel ativo e interativo nas mudanças que ocorrem no contexto em que está inserido. A interação entre a pessoa e os ambientes é, então, bidireccional, ou seja, da mesma forma que as estruturas ambientais influenciam no desenvolvimento e comportamento do individuo, este também pode provocar alterações no seu contexto. (BRONFENBRENNER, 1996 apud FREIRE E AIRES, 2012).

Portanto, compreende-se a partir deste pensamento que, para o enfrentamento do Bullying nas escolas, é necessário considerar o aluno/adolescente como um ser ativo em posição de mudar a realidade a que se encontra através de ajuda externa, no caso, cita-se o psicólogo educacional.

Segundo a Federação Mundial de Musicoterapia, 2011, a

"Musicoterapia é a utilização da música através de seus elementos constituintes (ritmo, melodia e harmonia) por musicoterapeuta qualificado em um processo destinado a facilitar e promover comunicação, relacionamento, aprendizado, mobilização, expressão, organização e outros objetivos terapêuticos relevantes, com o fim de 
atender às necessidades físicas, emocionais, mentais, sociais e cognitivas do paciente. A musicoterapia busca desenvolver potenciais e/ou restaurar funções do indivíduo para que ele ou ela alcance uma melhor qualidade de vida através da prevenção, reabilitação ou tratamento de doenças." (BRUSCIA, 1998)

Com a Portaria 849 de Março de 2017, a Musicoterapia torna-se integrante das Práticas Integrativas e Complementares do Sistema de Saúde (SUS) (BRASIL, 2017).

Já é sabido que a arte é uma forma de expressão humana que vem de encontro com a necessidade do homem de comunicar suas emoções, dores e sentimentos. Ela também é aspecto cultural e promove a interação entre as pessoas.

A música na adolescência se faz presente quase que em todos os momentos, nas atividades domésticas, no estudo, na convivência entre os jovens e, no lazer. Ela é forma de lidar com emoções, de expressar pontos de vista, de necessidades e desejos.

Neste estudo, portanto, objetivou-se realizar um levantamento de literatura a respeito da musicoterapia no enfrentamento do Bullying e violência nas escolas.

\section{MÉTODO}

Ao procurar compreender como a musicoterapia pode auxiliar no processo de enfrentamento do Bullying, este estudo se propôs a realizar uma revisão integrativa, método sistemático de busca, seleção e sumarização de resultados (DAL SASSO, CAMPOS, GALVÃO, 2008). Esse método é oriundo das ciências da saúde, fazendo parte da Medicina Baseada em Evidências, que surgiu em uma época de grande produção científica, onde havia e continua havendo, a necessidade de métodos de síntese de conhecimento e busca das melhores evidências. Tal produção científica, ao passar pelo filtro orientado por uma busca específica, é capaz de esclarecer as práticas e auxiliar nas tomadas de decisões.

Para orientar a busca foi utilizado o acrônimo PCC, que representa, na ordem em que aparece, População, Conceito e Contexto. Sendo eleito para este estudo, População: adolescente entre 10 a 19 anos como estabelecido pela Organização Mundial de Saúde (WHO 1986), Conceito: musicoterapia ou a música como ferramenta de enfrentamento e Contexto: escola.

A escola foi eleita como contexto, por ser o meio pelo qual o adolescente transita e onde, geralmente ocorre o Bullying.

Como base de dados, foi selecionado o PUBMED por conter o maior número de publicações na área da saúde; e a revista Music Therapy Perspectives, que é uma revista específica de musicoterapia com um grande número de publicações.

Como critérios de inclusão, foram determinados: 1) artigos 2) que apresentem o método de intervenção 3) relacionados com Bullying ou violência 4) que foram aplicados em contexto escolar. Como critérios de exclusão: 1) Intervenção que ocorreu em dois contextos diferentes, como por exemplo, na escola e em casa 2) que tenha sido individual

Os descritores foram selecionados a partir do Decs (Descritores em Saúde), sendo: Adolescent; Violence; Schools.

Foram selecionados artigos nos idiomas inglês, português e espanhol.

A informações extraídas foram: Local/País; Tipo de escola; Desenho Metodológico; População; Tipo de Intervenção; Local de Intervenção; Tipos de Bullying; Histórico de Vida dos Participantes; Quadro Clínico dos Participantes; Objetivo da Terapia; Tipos de Experiência Musical Utilizadas; Resultados da Intervenção Musicoterapêutica.

Foram utilizadas as estratégias de busca:

1. PubMed: ("Adolescent"[Mesh] AND ("Music"[Mesh] OR "Music Therapy"[Mesh])) AND "Violence"[Mesh]

2. Music Therapy Perspectives - Busca Avançada: Adolescent; Music; Music Therapy; Violence; School

\section{RESULTADOS}

Foram identificados 73 artigos, sendo eliminados 0 duplicados, dos quais 14 foram selecionados por título, sendo excluídos 12 por não atenderem a pergunta de pesquisa referente ao Contexto: Escola. Foram selecionados 2 artigos, sendo localizados, lidos na íntegra e extraídas as informações (Figura 1). 
llustração de Busca

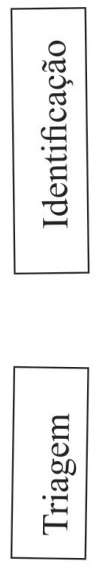

Artigos Identificados (PubMed = 31) $($ MTJ=42) $n=73$

$\downarrow$

Artigos após eliminação dos duplicados $(n=73)$
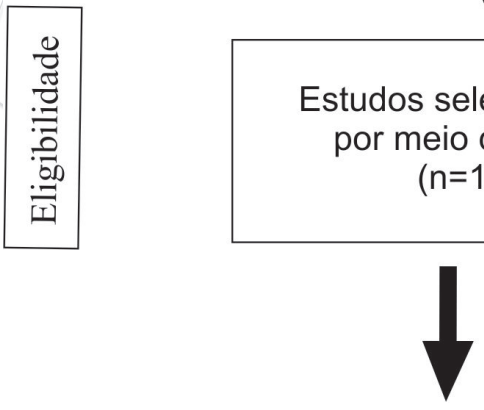

$N^{\circ}$ de artigos selecionados para verificação dos critérios de inclusão $(n=14)$

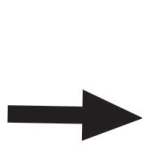

Artigos Excluídos $(n=59)$

$n=14)$
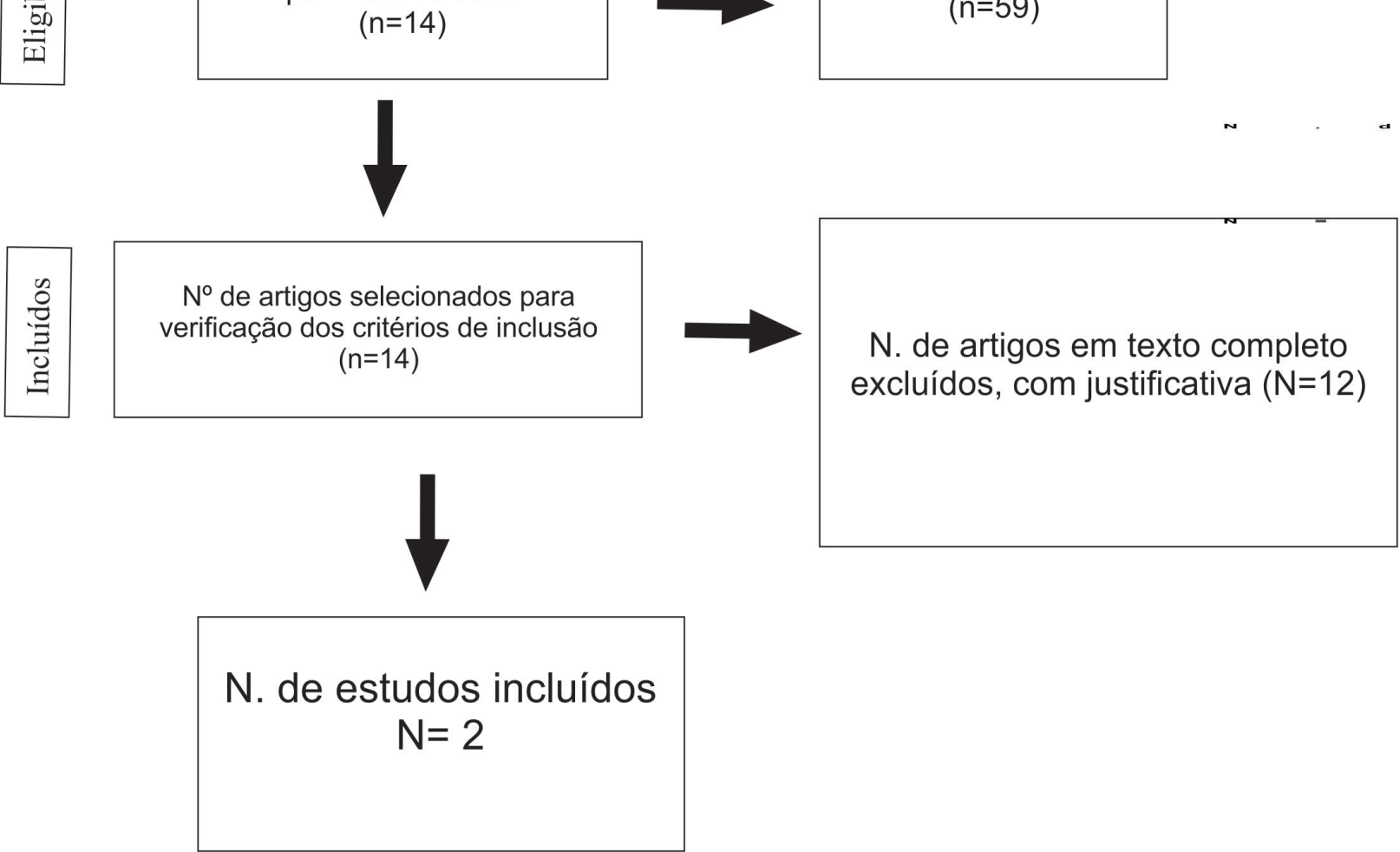

Figura 1 - Fluxograma da Revisão Integrativa, São Paulo, SP,

Brasil, 2019 
As informações extraídas foram organizadas, sumarizadas e serão apresentadas abaixo. A primeira sumarização reuniu informações como: Identificação do estudo (ID) Título, Autor, Ano de Publicação, Revista e Resumo. (Quadro1)

\begin{tabular}{|c|c|c|c|c|c|}
\hline ID & Titulo & Autor & Ano & Revista & Resumo \\
\hline 1 & $\begin{array}{l}\text { Empathy and } \\
\text { Aggression in } \\
\text { Group Music } \\
\text { Therapy with } \\
\text { Teenagers: } \\
\text { A Descriptive } \\
\text { Phenomenological } \\
\text { Study }\end{array}$ & $\begin{array}{l}\text { dos Santos, } \\
\text { Andeline } \\
\text { (DOS } \\
\text { SANTOS, } \\
2019 \text { ) }\end{array}$ & 2019 & $\begin{array}{l}\text { Music } \\
\text { Therapy } \\
\text { Perspectives }\end{array}$ & $\begin{array}{l}\text { Este estudo fenomenológico descritivo examinou as } \\
\text { experiências de adolescentes em musicoterapia de } \\
\text { grupo em uma escola em Eersterust, África do Sul. } \\
\text { O estudo centrou-se nas experiências de agressão, } \\
\text { empatia e as relações entre eles, através de uma } \\
\text { análise de dados de vídeo das sessões. Experiências } \\
\text { interconectadas de agressão e empatia ocorreram } \\
\text { em um mundo da vida colorido por dor emocional } \\
\text { subjacente, falta de pertencimento, conexão e apoio. } \\
\text { Instâncias de agressão e empatia também ocorreram } \\
\text { no contexto de experiências ambivalentes relativas } \\
\text { ao desejo de lutar; em relação a experiências de } \\
\text { poder, independência e autonomia; e no contexto } \\
\text { das experiências de explorar o que avançar na vida, } \\
\text { pode ou não implicar. Implicações para a prática de } \\
\text { musicoterapia estão incluídas. }\end{array}$ \\
\hline 2 & \multirow[t]{2}{*}{$\begin{array}{l}\text { "Being a bully } \\
\text { isn't very cool...": } \\
\text { Rap \& Sing } \\
\text { Music Therapy } \\
\text { for enhanced } \\
\text { emotional self- } \\
\text { regulation in } \\
\text { an adolescent } \\
\text { school setting } \\
\text { - a randomized } \\
\text { controlled trial }\end{array}$} & $\begin{array}{l}\text { Uhlig, Sylka; } \\
\text { Jansen, Erik; } \\
\text { Scherder, } \\
\text { Erik (UHLIG, } \\
\text { JANSEN e } \\
\text { SCHERDER, } \\
\text { 2018) }\end{array}$ & 2018 & $\begin{array}{l}\text { Psychology } \\
\text { of Music }\end{array}$ & \multirow{2}{*}{$\begin{array}{l}\text { A música como uma ferramenta autorreguladora } \\
\text { eficaz para emoções e adaptação comportamental } \\
\text { para adolescentes pode melhorar as habilidades } \\
\text { relacionadas à emoção quando aplicada como uma } \\
\text { intervenção na escola. Este estudo investigou o Rap } \\
\text { \& Sing Music Therapy em um programa baseado na } \\
\text { escola, para apoiar habilidades de autorregulação } \\
\text { para o bem-estar. Cento e noventa adolescentes da } \\
\text { oitava série de uma escola pública na Holanda foram } \\
\text { aleatoriamente designados para um grupo experimental } \\
\text { envolvendo Rap \& Sing Music Therapy ou um grupo } \\
\text { controle. Ambas as intervenções foram aplicadas a seis } \\
\text { turmas uma vez por semana durante quatro meses. As } \\
\text { medições no início do estudo e novamente após quatro } \\
\text { meses forneceram dados sobre os resultados do bem- } \\
\text { estar psicológico dos adolescentes, auto-descrição, } \\
\text { auto-estima e regulação emocional. Diferenças } \\
\text { significativas entre os grupos no teste do professor do } \\
\text { SDQ indicaram um grupo estabilizado de Rap \& Sing } \\
\text { Music Therapy, em oposição ao aumento de problemas } \\
\text { no grupo controle (p = 0,001; np2 = 0,132). Os } \\
\text { escores totais de todos os testes indicaram melhorias } \\
\text { significativas no grupo Rap \& Sing Music Therapy. Os } \\
\text { resultados do RCT implicam benefícios gerais da Rap } \\
\text { \& Sing Music Therapy em um ambiente escolar. Houve } \\
\text { efeitos aprimorados em todas as medidas - como estão } \\
\text { de acordo com intervenções escolares de envolvimento } \\
\text { motivacional em temas comportamentais, emocionais e } \\
\text { sociais - um resultado promissor. }\end{array}$} \\
\hline & & & & & \\
\hline
\end{tabular}

Quadro 1. Caracterização dos estudos analisados, Brasil, São Paulo, SP, 2019. 
No próximo quadro estão listadas as informações extraídas: ID, Local/País, Tipo de Escola, Desenho Metodológico, População, Tipo de Intervenção e Local de Intervenção.

\begin{tabular}{|c|c|c|c|c|c|c|}
\hline ID & Local/País & $\begin{array}{l}\text { Tipo de } \\
\text { Escola }\end{array}$ & $\begin{array}{l}\text { Desenho } \\
\text { Metodológico }\end{array}$ & População & Tipo de Intervenção & $\begin{array}{l}\text { Local de } \\
\text { Intervenção }\end{array}$ \\
\hline 1 & $\begin{array}{l}\text { Sul da áfrica/ } \\
\text { Eersterust }\end{array}$ & $\begin{array}{l}\text { Ensino } \\
\text { Médio }\end{array}$ & $\begin{array}{l}\text { Descritivo } \\
\text { fenomenológico } \\
\text { a partir da } \\
\text { análise de } \\
\text { gravações das } \\
\text { sessões de } \\
\text { musicoterapia }\end{array}$ & $\begin{array}{l}6 \text { adolescentes do } \\
\text { sexo masculino e } \\
\text { feminino entre } 15 \\
\text { e } 18 \text { anos }\end{array}$ & $\begin{array}{l}\text { Grupo de Musicoterapia } \\
\text { na escola; } 11 \text { sessões } \\
\text { semanais com duração } \\
\text { aproximada de } 40 \\
\text { minutos às } 1 \text { hora e } 10 \\
\text { minutos. }\end{array}$ & $\begin{array}{l}\text { Na escola, } \\
\text { dentro da sala } \\
\text { de aula e hall } \\
\text { da escola. }\end{array}$ \\
\hline 2 & $\begin{array}{l}\text { Países } \\
\text { Baixos/ } \\
\text { Nijmegen }\end{array}$ & $\begin{array}{l}\text { Ensino } \\
\text { Fundamental }\end{array}$ & $\begin{array}{l}\text { Estudo } \\
\text { randomizado } \\
\text { controlado }\end{array}$ & $\begin{array}{l}65 \text { adolescentes } \\
\text { do sexo masculino } \\
\text { e feminino entre } \\
8 \text { e } 13 \text { anos } \\
\text { foram incluídos } \\
\text { e analisados } \\
\text { no grupo de } \\
\text { musicoterapia. }\end{array}$ & $\begin{array}{l}3 \text { grupos de } \\
\text { musicoterapia composto } \\
\text { por até } 30 \text { jovens em } \\
\text { cada classe em } 8 \\
\text { sessões semanais de } \\
45 \text { minutos e outras } 8 \\
\text { sessões com } 15 \text { jovens } \\
\text { em cada grupo. }\end{array}$ & $\begin{array}{l}\text { Nas escolas, } \\
\text { dentro das } \\
\text { salas de aulas }\end{array}$ \\
\hline
\end{tabular}

Quadro 2. Caracterização dos estudos quanto Localização Geográfica, Método Científico, População Incluída e Local de Intervenção, Brasil, São Paulo, SP, 2019.

Foram também extraídas informações como: Tipo de Bullying Praticado, Histórico de Vida dos Participantes dos Estudos, Quadro Clínico dos Participantes, Objetivo da Terapia, Tipos de Experiências Musicais Utilizadas e, Resultados da Intervenção Musicoterapeutica, listados abaixo.

\section{Tipos de Bullying praticados}

No Estudo 1 os alunos participantes apresentavam agressividade verbal e física contra professores, amigos de classe e outros alunos. O Estudo 2 abordou o contexto escolar em geral, não de modo específico e, que incluia jovens com problemas de comportamento e, déficit de atenção. Neste estudo foram incuídos tanto jovens com alguma questão comportamental quanto jovens sem problemas identificados.

\section{Histórico de Vida dos Participantes}

No Estudo 1 foi realizado um levantamento do histórico de vida de cada participante, onde foram identificados: jovens que sofreram abuso sexual; tiveram perda de entes queridos e que representavam proteção; tiveram pais que se suicidaram; sofreram abandono por um dos pais e; tiveram um dos pais assassinado. No Estudo 2 não foram apresentados detaIhes dos participantes embora tenha sido realizado um levantamento através do SDQ (Strength and Difficulty Questionaire), que foi respondido pelos participantes, pais e professores. Este questionário auxiliou a identificar os escores de problemas sociais e emocionais dentre os participantes.

\section{Quadro Clínico dos Participantes}

No Estudo 1, foram identificados jovens que: praticavam automutilação; tinham ideação suicida; apresentavam Transtorno do Déficit de Atenção com Hiperatividade (TDAH) e; drogadição. Além de apresentarem sintomas associados ao Bullying como agressividade contra colegas e professores.

No Estudo 2, nenhum dado específico do questionário foi identificado. 


\section{Objetivo da Terapia}

No Estudo 1, os objetivos são descritos juntamente com a apresentação das técnicas utilizadas e das respostas e modos de interação entre os participantes. Somente para citar alguns, os objetivos foram auxiliares na evocação de sentimentos e pensamentos sobre relações interpessoais, experiências na escola e sentimentos. $O$ estudo seguiu uma abordagem orientada pela teoria humanista.

No Estudo 2, os objetivos foram mais concretos e visavam auxiliar nas habilidades de autorregulação através da modulação de emoções negativas como ansiedade, tristeza e raiva. As técnicas foram selecionadas para promover: coesão e cooperação de grupo; expressar sentimentos através da expressão corporal; engajamento emocional; mudança de humor; auto-estima e; habilidade de resolucionar problemas. Bem como, ampliar a consciência sobre estados emocionais e comportamento; estimular a empatia e tomada de decisões. O estudo foi orientado pela abordagem cognitivo-comportamental.

\section{Tipos de Experiências Musicais Utilizadas}

No Estudo 1, diversas atividades musicais foram proporcionadas, dentre as quais: Improvisação instrumental livre e temática; escuta musical; percussão; composição. No Estudo 2, foi proposta uma Intervenção terapêutica utilizando o rap e o canto, com foco em temas individuais e outras temáticas propostas pelos musicoterapeutas. Dentre as atividades, a intervenção proporcionou práticas ritmicas, técnica vocal e, aprendizado de rima de palavras para a escrita de letras de rap.

\section{Resultados da Intervenção Musicoterapêutica}

No Estudo 1, participantes puderam compartiIhar experiências sobre a violência que os cerca em sua comunidade; seus sentimentos em relação aos abusos, negligência e violência sofrida de acordo com suas histórias pessoais. A musicoterapia auxiliou no autoconhecimento, no desenvolvimento da empatia e consequente controle da raiva e da agressividade.

No Estudo 2, o grupo controle teve um aumento no escore de problemas relacionados à falta de aten- ção e sintomas emocionais ao longo do período; maior tempo de permanência de problemas; maior dificuldade em obedecer ordens quando em estado de estresse, em comparação ao grupo que estava recebendo musicoterapia. Em entrevista, os adolescentes demonstraram que a musicoterapia ofereceu uma experiência positiva, aprenderam a lidar com suas emoções, desenvolver autoconhecimento, expressar emoções em palavras e, liberdade de expressar o que sente.

\section{DISCUSSÃO}

A partir do levantamento bibliográfico, foi possível compreender que 1) a musicoterapia pode ocorrer em escolas 2) Em um programa elaborado entre 10 a 16 sessões é possível obter resultados positivos em relação à agressividade e problemas comportamentais 3) o processo musicoterapêutico é agradável aos jovens, facilita a interação e coesão de grupo, proporcionando melhor compartilhamento de história de vida e sentimento, auxiliando na empatia e autoconheicmento, importante aspecto para redução da agressividade e violência nas escolas 4) foram utilizadas técnicas diversas de música.

Pudemos observar nos estudos, que a prática do Bullying geralmente decorre de um problema pessoal do agressor e pode ser tratada junto aos problemas de comportamento no próprio contexto escolar e junto aos profissionais e/ou programas voltados para melhoria do quadro apresentado.

Percebemos que a musicoterapia, dentro de um programa com objetivos específicos para tratar questões relacionadas à problemas de comportamento, violência e agressividades nas escolas, tal como identificado nos estudos, é uma terapia agradável aos jovens, justamente por utilizar a música e seus elementos, engajando os jovens em experiências musicais capazes de desafiar a cognição, a capacidade de interação e colaboração. É ferramenta que sensibiliza, promove a empatia e ajuda a comprender as próprias emoções e sentimentos. Também é meio que habilita a capacidade de expressão e capacita o jovem a relacionar-se socialmente, bem como, a lidar com os própios impulsos.

A musicoterapia em ambiente escolar se enquadra no que é classificado como Práticas Ecológicas, que consistem no uso da musicoterapia para promo- 
ver saúde em comunidades e ambientes comunitários. Neste caso o foco não está em um cliente individual, mas em membros que pertencem a um determinado espaço comum (BRUSCIA, 1998). A característica que se denomina "ecológica" é o grupo terapêutico acontecer no ambiente onde vivem, estudam e trabalham essas pessoas. Tal perspectiva, é derivada da teoria sistêmica onde os individuos são vistos vinculados entre si sendo possuidores de vários níveis de influência recíproca.

Segundo a UNESCO, a suspensão de alunos problemáticos de escolas apenas transfere o problema para outro lugar. É necessário que a escola, aprenda a lidar ou criar mecanismos para resolução do problema. Agir dentro da escola é essencial para lidar com o Bullying e promover a qualidade na educação (UNESCO, 2017, p. 13). À escola também é atribuida a função de desenvolver habilidades dos jovens em comunicar-se e resolver problemas de modo pacífico, inclusive criar valores de tolerância, respeito e solidariedade, promovendo a não violência. No entanto, muitas vezes, escolas têm dificuldades de lidar com diversos problemas (ARROYO, 2014), são problemas de diversas naturezas: sociais, estruturais, curriculares, familiares, cujo olhar de um profissional da saúde poderia auxiliar professores e diretores, que sozinhos, muitas vezes, não conseguem lidar com o problema da violência.

Segundo a psicologia escolar é necessário que o psicólogo atue no próprio ambiente escolar (FREIRE E AIRES, 2012) para que possa compreender a dinâmica das relações, promover reflexão, conscientizar agentes institucionais, compreender conflitos institucionais, bem como, conhecer as características culturais da escola e a relação da mesma com a comunidade e os familiares dos estudantes. Da mesma forma, o musicoterapeuta deverá estar ciente e trabalhando dentro do contexto escolar, junto com o psicologo (se houver), ou mesmo traçando propostas que venham de encontro com as diferentes realidades de cada sistema escolar e comunitário.

Apesar de não terem sido identificados estudos no Brasil sobre Musicoterapia na escola ou junto a programas baseados em escola, este trabalho gostaria de reforçar o fato de que a musicoterapia entrou nas PICS e a escola pode sediar o atendimento musicoterapeutico através desta Portaria. Neste caso, é necessário que os membros da comunidade escolar e musicoterapeutas que atendam ou pretendam atender a comunidade, apresentem a importância da musicoterapia no contexto e, assim, seja realizado o cadastramento pelo profissional do SUS responsável, como constam nos regulamentos de implantação (MINISTÉRIO DA SAÚDE, 2006).

\section{Limitações}

A temática sobre a relação entre música, jovem e violência é muito ampla, inclusive considerando os aspectos da música que podem influenciar negativamente o comportamento, bem como, os inúmeros recursos positivos que ela pode atender. Nesta pesquisa foram considerados apenas estudos com intervenção da musicoterapia.

A musicoterapia é uma terapia menos confrontadora para os jovens. A música sensibiliza, promove a empatia e acessa o sentimento, as letras de música permitem abrir para uma discussão sobre determinado assunto. Ao compor uma música, por exemplo, é possível colocar nela temas que precisam ser expressados, que os jovens necessitam comunicar, cuja experiência também os habilita a expressar-se quando sentirem necessidade de comunicar-se com parentes, colegas e, professores.

A escola, pode ser um bom lugar para o desenvolvimento de projetos de musicoterapia, para trabaIhar problemas encontrados no contexto, promover o desenvolvimento de habilidades sociais e, abrir um espaço agradável para compartilhamento de questões biopsicossociais, como o Bullying, que podem afetar profundamente a vida dos jovens e da sociedade como um todo. A escola é o local onde o Bullying se manifesta timidamente e ganha proporções devastadoras, mas também pode ser o local onde se criam as relações de afeto necessárias para a integridade emocional e psicológica e necessárias para a vida adulta. A musicoterapia pode proporcionar experiências positivas no contexto biopsicossocial da escola promovendo a saúde. 


\section{REFERÊNCIAS}

ALMEIDA, Kathanne Lopes; CAVALCANTE, Anamaria; SILVA, Jocileide Sales Campos. Importância da identificação precoce da ocorrência do Bullying: uma revisão de literatura The importance of early identification of Bullying: a review of the literature. $\mathbf{R e v} \mathbf{P e}-$ diatr, v. 9, n. 1, p. 8-16, 2008.

ARROYO, Margarete. Juventudes, músicas e escolas: análise de pesquisas e indicações para a área da educação musical. Revista da ABEM, v. 17, n. 21, 2014. Disponível em: http://www.abemeducacaomusical.com.br/revistas/revistaabem/index.php/revistaabem/article/view/236. Acesso em: 19 abr. 2019.

BRASIL. Ministério da Saúde. Secretaria de Atenção à Saúde. Departamento de Atenção Básica. Política Nacional de Práticas Integrativas e Complementares no SUS - PNPIC-SUS /Ministério da Saúde, Secretaria de Atenção à Saúde, Departamento de Atenção Básica. - Brasília: Ministério da Saúde, 2006.

BRUSCIA, Kenneth E. Definindo Musicoterapia. Rio de Janeiro: Enelivros, 1998.

BRASIL. Portaria $n^{\circ} \mathbf{8 4 9}$, de 28 de março de 2017. Inclui a Arteterapia, Ayurveda, Biodança,Dança Circular, Meditação, Musicoterapia,Naturopatia, Osteopatia, Quiropraxia, Reflexoterapia,Reiki, Shantala, Terapia Comunitárialntegrativa e Yoga à Política Nacionalde Práticas Integrativas e Complementares. Diário Oficial da União, 28 mar. 2017.

DAL SASSO MENDES, Karina; SILVEIRA, Renata Cristina de Campos Pereira; GALVÃO, Cristina Maria. Revisão integrativa: método de pesquisa para a incorporação de evidências na saúde e na enfermagem. Texto \& Contexto Enfermagem, v. 17, n. 4, 2008. Disponível em: http://www.redalyc.org/resumen. oa?id=71411240017. Acesso em: 18 dez. 2018.
SANTOS, Andeline dos. Empathy and Aggression in Group Music Therapy with Teenagers: A Descriptive Phenomenological Study. Music Therapy Perspectives, v. 37, n. 1, p. 14-27, 2019.

ESTATUTO DA CRIANÇA E DO ADOLESCENTE - Lei 8069/90 | Lei n 8.069, de 13 de julho de 1990, Presidência da República. Jusbrasil. Disponível em: https://presrepublica.jusbrasil.com.br/legislacao/91764/estatuto-da-crianca-e-do-adolescente -lei-8069-90. Acesso em: 19 abr. 2019.

FREIRE, Alane Novais; AIRES, Januária Silva. A contribuição da psicologia escolar na prevenção e no enfrentamento do Bullying. Psicologia Escolar e Educacional, v. 16, n. 1, p. 55-60, 2012.

INSTITUTO BRASILEIRO DE GEOGRAFIA E ESTATÍSTICA (Org.). Pesquisa nacional de saúde do escolar, 2015. Rio de Janeiro: IBGE, 2016.

CONFERENCE UNITED NATIONS EDUCATIONAL, SCIENTIFIC AND CULTURAL ORGANIZATION. School Violence and Bullying - Global Status Report. place de Fontenoy, 75352 Paris 07 SP, France, 2017. Disponível em: https://unesdoc.unesco.org/ ark:/48223/pf0000246970. Acesso em: 15 fev. 2019.

UHLIG, Sylka; JANSEN, Erik; SCHERDER, Erik. "Being a bully isn't very cool...": Rap \& Sing Music Therapy for enhanced emotional self-regulation in an adolescent school setting - a randomized controlled trial. Psychology of Music, v. 46, n. 4, p. 568-587, 2018.

WORLD HEALTH ORGANIZATION. Young People's Health - a Challenge for Society. Report of a WHO Study Group on Young People and Health for All. 1986; Technical Report Series 731. Disponível em: https://apps.who.int/iris/handle/10665/41720. Acesso em: 15 fev.2019. 